Journal Home Page:

http://perlinguam.journals.ac.za

\section{Per \\ Linguam}

A Journal for Language Learning Tydskrif vir Taalaanleer

\title{
EDUCATORS' PERCEPTIONS OF THE FOUNDATION PHASE ENGLISH HOME LANGUAGE CURRICULUM AND ASSESSMENT POLICY STATEMENT
}

Radhamoney Govender \& Anna J Hugo

University of South Africa

Numerous transitions in South Africa's basic education curriculum development have been criticised for failing to meet stakeholders' expectations. Questions have arisen as to whether the latest Curriculum and Assessment Policy Statement (CAPS) is functioning effectively in Foundation Phase classrooms and whether it will improve the quality of education and transform the country's schools. For an in-depth understanding of educators' perceptions of the Foundation Phase English Home Language CAPS document and workbook, 13 educators from five English-medium primary schools in Port Shepstone, KwaZulu-Natal, were interviewed. They criticised the structure of the phonics and the highly pressurised programme. In particular, they advocated the return to a more systematic method of teaching phonics and a reduction in the number of assessments demanded. Another issue highlighted by the educators is the overrigorous pace and rigid structure of the Foundation Phase English Home Language CAPS document, especially for the first two terms of Grade 1. The added value of this study is its bringing on board, for the first time, the views of experienced educators directly involved in the hands-on implementation of the English Home Language CAPS.

Keywords: Outcomes-based Education, Revised National Curriculum Statement, Curriculum and Assessment Policy Statement, Foundation Phase

\section{INTRODUCTION}

South Africa's school curriculum has undergone as many as four transitions since democracy. In 1997, it changed from the traditional Christian National Education curriculum to Outcomes-based Education (OBE). A few years later, OBE was replaced with the Revised National Curriculum Statement (RNCS), which became policy in 2002. In 2007, the new National Curriculum Statement (NCS) was introduced, which in turn made way for the Curriculum and Assessment Policy Statement (CAPS) in 2012. Amendments continued to be made to improve the curriculum after 1994, but the questions arise yet again: Is the new curriculum functioning effectively and how is it functioning in the Foundation Phase classroom?

When a curriculum is designed or changed, consultation is imperative with persons working at various levels in the national and provincial education departments, experts in curriculum design, and people in higher education institutions who train educators, practitioners, academics and policy-makers. All these bring different perspectives to the curriculum, along with a variety of cultural agendas and aspirations for young children's development (Wood \& Hedges, 2016: 15). However, as confirmed by Maharajh, Nkosi and Mkhize (2016: 380), those who work at the 
micro level, that is, in schools, are often not adequately consulted. Consequently, implementation that follows a top-down approach may lead to disappointing results. Educators are the people who have to put the curriculum into practice in the classroom. Their buy-in as to what the curriculum entails, how it functions and what it requires determines the success of the learners in the classroom (Fleisch, 2008: 123). No published research was found on educators' input relating to the Foundation Phase English Home Language CAPS, the country's latest curriculum innovation.

This article reports on Foundation Phase educators' opinions about the CAPS document and workbook used for teaching English as the home language, based on interviews with 13 educators from five schools in KwaZulu-Natal. Although the sample size was small, their opinions provide important preliminary input about the challenges that CAPS needs to overcome if it is to succeed where other curricula have failed.

There is a dearth of published academic articles on the effects of CAPS and its implementation. The limited scholarly literature on CAPS offers broad analysis of educators' views and implementation of the curriculum. To the best of our knowledge, the present study is the first to focus on reports by experienced, practising educators on specific elements in any specific subject and phase. The importance of the Foundation Phase is that, in this phase, learners begin to develop formal reading and writing skills. The curriculum must cater sufficiently for the development of these skills, as they form the basis for all subsequent educational achievement. Our study is significant in that it highlights aspects of the Foundation Phase English Home Language CAPS document and workbook that may require amendment in order to succeed in improving learners' literacy skills.

The study was guided by the following research questions: What were the opinions of educators in selected English-medium schools about the Foundation Phase CAPS document and workbook as experienced in practice, and what recommendations for improvement could these educators offer?

\section{CURRICULUM DEVELOPMENT AND TEACHING MODELS OF CURRICULUM DESIGN IN SOUTH AFRICA}

The curriculum is concerned with what is planned, implemented, taught, learned, evaluated and researched in schools at all educational levels (McKernan, 2008: 4). Curricula represent the different programmes and learning opportunities or teaching programmes that can provide for the education needs of the target group (Steyn, Steyn \& De Waal, 2001: 97). Donald, Lazarus and Lolwana (2010: 21) believe that the curriculum is often misunderstood as referring only to the syllabus or the content of what is taught. They assert that a curriculum is much more than this, as it relates to the aims and purpose of the entire schooling programme. Thus, apart from content, the curriculum includes the structure of the programme, processes and methods of teaching and learning, methods of assessment and evaluation, processes of planning and decision-making that may be involved, and a range of factors that characterise it. The curriculum forms the basis of teaching and learning, and curriculum development is the process of planning, implementing and evaluating the curriculum that ultimately results in a curriculum plan (Lunenburg, 2011: 1). 
Curriculum models used by curriculum planners to develop a curriculum help them to systematically and transparently map out the rationale for the use of particular teaching, learning and assessment approaches (O'Neil, 2010: 1). The three curriculum models introduced in South Africa since 1996 are: Outcomes-based Education; the Revised National Curriculum Statement and the National Curriculum Statement; and most recently, the Curriculum and Assessment Policy Statement.

\section{Outcomes-based Education}

For Spady (2007: 1), OBE means clearly focusing and organising everything in an educational system around what is essential for all learners to succeed at the end of their learning experiences. This implies starting with a clear picture of what is important for learners to be able to do, then organising the curriculum, instruction and assessment to ensure that this learning ultimately happens. For an outcomes-based system, a clear set of learning outcomes is developed, and conditions and opportunities are established that enable and encourage all learners to achieve them (Spady, 1994: 1-2).

Underpinned by Spady's (1994) philosophy of OBE, South Africa developed its own OBE model, referred to as Curriculum 2005 (C2005). In 1996, the government decided to turn the country's entire education system into an outcomes-based one. C2005 was expected to address the inequality resulting from the previous apartheid education system and to underpin economic growth by developing much-needed skills among learners and educators (Steyn et al., 2001: 88). This model was selected not only to emancipate learners and educators from a content-based mode of operation, but also as a response to international trends in educational development (Botha, 2002: 362).

The general level of misunderstanding of Spady's ideas as well as implementation problems led to disarray and calls to abandon OBE. As early as 1998, Jansen (1998: 1-11) criticised the policy for being driven by political imperatives that had little to do with realities of classroom life. In addition, the term 'transformational OBE' created considerable confusion in South Africa, where the word 'transformation' was mainly associated with the recent shift from apartheid to democracy (Spady, 2007: 4). Killen (1998: 3) concluded that the opposition to Spady's ideas had two main causes - fear of change, and the unwillingness of many educators to try to understand Spady's vision.

In 2000, the Report of the Ministerial Committee established to review C2005 provided a wideranging critique of the curriculum (Chisholm, 2003: 3). It argued that the implementation of OBE was hindered by a skewed curriculum structure and design, lack of correlation between curriculum and assessment policy, inadequate training of educators, learning support materials that varied in quality or were unavailable, policy overload and limited transmission of learning into classrooms, and scarcity of personnel and resources to implement and support C2005 (Chisholm, 2003: 3-4). These reactions and criticisms of the OBE model resulted in its early demise.

Per Linguam 2018 34(1):17-32

http://dx.doi.org/10.5785/34-1-767 


\section{The Revised National Curriculum Statement and the National Curriculum Statement}

To address the many OBE issues raised, the Review Committee proposed the introduction of a revised curriculum structure, the RNCS, to overcome one of the fundamental design flaws of C2005 by specifying the knowledge content more explicitly (Jansen \& Taylor, 2003: 40).

The RNCS was not a new curriculum but a streamlining and strengthening of C2005 (Department of Education, 2002: 6). It kept intact the principles, purposes and thrust of C2005 and affirmed the commitment to OBE. It aimed to develop the full potential of each learner as a citizen of a democratic South Africa (Department of Education, 2002: 8), and to create a lifelong learner who is confident and independent, literate, numerate and multi-skilled, compassionate with a respect for the environment, and able to participate critically and actively in society. The review of the OBE philosophy which was initially iterated in the form of RNCS was later changed to NCS.

Shortcomings associated with RNCS implementation provided an important context for its review (Department of Education, 2009: 13). First, there was no lucid and comprehensive implementation plan for RNCS. The significance of RNCS was not emphasised and the message supporting its implementation was that it was not a new curriculum. This resulted in the blending of RNCS into C2005 by educators and district, provincial and national Department of Education officials. The various stakeholders developed their own interpretations of RNCS, which led to widespread confusion about what constituted the official policy. Second, assessment support and guidance were not exhaustive enough and no assessment policy was developed by the specialists who had written the curriculum. Third, educator training was superficial, and did not elucidate the points of departure and the newness of RNCS. Finally, the language policy, specified in RNCS, was not communicated and not implemented. The report of the task team for the review of the implementation of RNCS was insistent that the confusion and uncertainty about the curriculum be addressed (Department of Education, 2009: 49).

\section{Curriculum and Assessment Policy Statement and English Home Language teaching in the Foundation Phase}

After much deliberation, CAPS was introduced in South Africa in 2012. It is regarded as more prescriptive than OBE, which is seen as the more flexible of the two. Thus, Grussendorff (2014: 33) emphasises that skilled educators may find CAPS overly prescriptive and hence demotivating. A fundamental resource that is provided to assist educators in teaching in accordance with CAPS is the CAPS document. Each subject in each grade has a single, comprehensive and concise policy document with details on what educators need to teach (the learning content) and to assess, on a grade-by-grade and subject-by-subject basis (Variend, 2011: 1). There are clearly delineated topics for each subject, and the number and type of assessment tasks per term are stipulated. Furthermore, a variety of formal and informal assessment tasks are provided for various subjects. Educators are expected to teach the content and to assess learners as stipulated in the CAPS document. This ensures consistency in teaching and learning in every grade across regions and provinces.

In the Foundation Phase, educators are provided with CAPS documents for Home Language, Mathematics and Life Skills. The English Home Language CAPS document specifies what 
educators should teach and assess. A variety of activities and formal and informal assessments are provided for listening and speaking, phonics, reading, handwriting, and writing. With regard to reading, the document refers to shared reading, group-guided reading, and paired and independent reading. The importance of word recognition and, especially, comprehension during the reading process is also discussed.

The document contains no discussion of the difficult issue of non-English speaking Foundation Phase learners whose parents choose to send their children to schools where English is the language of learning and teaching. Fleisch (2008: 105) maintains that children whose home language is different from that of the school experience difficulty because of the ways in which second language learning actually takes place. This could pose major problems for non-English speaking learners in schools where English is the home language taught in the classroom as well as the medium of instruction. As Wium (2011:3) asserts, language is the foundation for learning and for developing competence in listening, speaking, reading and writing. Therefore, it is crucial that curriculum planners make provision for these concerns.

The Department of Basic Education has provided learners with CAPS workbooks. Each Foundation Phase learner is provided with two workbooks per subject per year. One workbook is distributed to learners in the first half of the year and the other workbook is given out in the second half of the year. Educators are expected to make optimal use of the workbooks. In the Foundation Phase, workbooks are provided for the Home Language, Mathematics, and Life Skills. The English Home Language workbooks comprise a variety of activities that include phonics, reading, handwriting and writing. The stories in the workbooks are accompanied by colourful pictures. In an ideal classroom, each learner should have his or her own workbook. However, in some schools there are insufficient workbooks for Foundation Phase learners, as was reported in 2012 by the National Education Evaluation and Development Unit (NEEDU) school evaluators, who visited the nine provincial offices, as well as 15 district offices and 133 schools to assess the extent to which the national and provincial policies were being implemented across the four levels (national, provincial, district and school) of the system (Taylor, 2013: 3). Their focus was on the Foundation Phase in urban primary schools. Having to share workbooks (Taylor, 2013: 7) poses a challenge when learners are expected to complete writing activities.

\section{METHODOLOGY}

\section{Research design}

This qualitative investigation took the form of a phenomenological study. The approach is used to understand and interpret the meaning that participants give to their everyday lives (Fouché, 2005: 270) and to understand the essence of experiences about a phenomenon (Nieuwenhuis, 2016: 75). It is a strategy of inquiry in which the researcher identifies this essence from the participants' perspectives (Creswell, 2009: 13). The researcher collects data on ways in which they make sense of a particular experience or situation (McMillan \& Schumacher, 2010: 24). In our study, interviews were the main means of data collection. The interview is the most prominent data gathering tool in qualitative research (Punch, 2009: 144), as it is viewed as an effective way of accessing people's perceptions, definitions of situations, and constructions of reality.

Per Linguam 2018 34(1):17-32

http://dx.doi.org/10.5785/34-1-767 
Ethical considerations were adhered to when conducting the research. Ethical clearance was obtained from the University of South Africa (Ethical Clearance number: 2014 August/31648606/MC). Permission to conduct the research was given by the KwaZulu-Natal Department of Education and each school principal, and the educators who participated in the research provided written consent.

\section{Study site and context}

The study was conducted in five English-medium primary schools (Schools A to E) in Port Shepstone, KwaZulu-Natal. These schools were within close proximity to each other. The Department of Basic Education (2011: 305) divides schools into five socioeconomic quintiles, depending on the degree of poverty in the community around the school. Quintile 1 is the poorest of the five quintiles. Schools A, B and C were classified as quintile 5 schools and School D as quintile 4; all four were suburban schools. School E, a quintile 2 school, was a non-fee-paying school situated in a semi-rural area. Quintile 4 and 5 schools are better resourced because the economic status of the parents enables them to pay school fees, which enables the management of the schools to provide additional resources and equipment. Our project included School E in an attempt to incorporate a wider range of schools. This small study served as a starting point for investigative procedures that could later be used in other schools.

The educator-to-learner ratios in the schools varied from 1:38 to 1:45. Schools A, B, C and D were well resourced in terms of catering for the educational needs of the learners but, although School E had the necessary infrastructure, it was incomparably less sophisticated than that of the other four schools. In School E, some of the classrooms were very small and overcrowded and the school did not have a well-resourced library. All the schools had competent principals, as well as highly qualified educators with varying degrees of experience.

Although four of the five schools were situated in predominantly Indian suburbs and the educators at all the schools were mostly Indian, their learner populations were relatively diverse, with greatly varied socio-economic backgrounds and distances to travel between home and school. Most of the learners were isiZulu-speaking, with access to schools close to their homes, but their parents preferred to enroll them in suburban English-medium schools further away, rather than in local schools where their home language was also the language of learning and teaching. These children, whose home language was not English, attended schools where English was taught as the home language and was also the language of instruction.

\section{Sampling and participants}

Following Gorman and Clayton's (2008: 128) advice that most qualitative studies use purposive sampling, this was our chosen method for selecting Foundation Phase educators from the five schools. Richness of professional background and willingness to participate in in-depth interviews were the primary considerations in identifying participants for the study, and we selected educators with more than five years of experience teaching English as a home language. Both male and female Foundation Phase educators were included. Dörnyei (2011: 127) asserts that an initial sample size of six or 10 can suffice for this kind of study, and Nieuwenhuis (2016: 75) confirms that a phenomenological study should comprise long interviews with up to 10 
participants. Sampling was conducted in tandem with data collection and continued until data saturation was reached.

The participants comprised 13 Foundation Phase educators (one man and 12 women) from the selected English-medium primary schools. Interviews were conducted with three educators from School A, two from School B, two from School C, three from School D, and three from School E. We were able to acquire the assistance of the Heads of Departments at the schools to link us with experienced educators. In this article, reference is made to Educators 1 to 13.

\section{Data collection}

Semi-structured one-to-one interviews were conducted in order to understand the issues from each participant's point of view and to extract the meaning of each educator's experiences. Individual interviews were preferred to focus groups for each educator to be able, in private, to express his/her feelings subjectively. A set of predetermined questions were prepared on an interview schedule. However, the researchers were free to digress and probe for more information and the participants were encouraged to clarify and elaborate in an exploratory manner about issues raised. The questions asked addressed matters specifically related to the Foundation Phase English Home Language CAPS document and workbook. Participants' biographical data were also obtained. Having been piloted earlier with educators from another school, each of the 13 interviews lasted for approximately an hour. All interviews were digitally recorded and transcribed verbatim.

\section{Data analysis}

According to Nieuwenhuis (2016: 109), data collection, processing, analysis and reporting are intertwined in qualitative studies and tend not to follow a fixed set of successive steps. In our study, data analysis was an ongoing and iterative process, involving reference back to the original field notes to verify conclusions. The topics embedded in the interview schedule were used for data analysis. Each transcript was read and the participants' responses to specific questions were highlighted so that themes could be found.

\section{RESULTS OF THE STUDY AND DISCUSSION}

The following three themes were retrieved from the interviews:

- Themes obtained from the biographical data.

- Educators' views on the Foundation Phase English Home Language CAPS document.

- Educators' views on the Foundation Phase English Home Language CAPS workbook.

\section{Biographical data}

Demographic information was collected about the participants in terms of school, gender, grade currently taught, training to teach learners who study through the medium of English as a second language (ESL), and ability to speak isiZulu. 
In these five schools, gender disparity was conspicuous. There were only three male Foundation Phase educators in the five schools and just one of them participated in the study. Of the 13 educators interviewed, three taught Grade 1 learners, four taught Grade 2 learners and six taught Grade 3 learners.

All the educators interviewed had substantial teaching experience, ranging from eight to 35 years, with an average of 20.7 years of teaching learners from Grade 1 to Grade 3. We were therefore satisfied that feedback about the curriculum, and especially about the use of the CAPS document, was based on expertise, and on knowledge and experience gained over an extended period.

Only five participants indicated that they had had training in teaching ESL learners. Although English was taught as the home language at all five schools and was also the language of learning and teaching, most of the learners were English second-language speakers. Although only five of the 13 educators were trained to teach learners who speak English as a second language, which could influence the methodology they used in the classrooms and the support provided to learners whose command of English was not up to standard, we assumed that their many years of experience in the teaching of English second language learners would have been a compensatory factor.

Three educators, whose home language was isiZulu, confirmed that their ability to speak isiZulu was excellent. Only one educator said that she spoke isiZulu well although she was not an isiZulu home language speaker. The remaining educators assessed their own ability to speak isiZulu as fair or very poor. These nine educators could not use code-switching to support learners who did not understand what was being taught or explained in English. In the opinion of the researchers, this could have influenced some of the isiZulu speaking learners' acquisition of English and their general comprehension of what was taught to them.

It could be argued that the fact that the classes had a large population of isiZulu-speaking learners was nothing new to the educators. What they were able to do was to assess the way CAPS works with equivalent groups of learners whom they had taught using previous curricula.

\section{Educators' views on the Foundation Phase English Home Language CAPS document}

Most of the educators felt that CAPS for English Home Language is not working effectively in the classroom for several reasons. Educators are required to use the CAPS document when teaching, as it is the only document prescribed by the Department of Basic Education. Not all educators found it user-friendly, even though they did their best to be guided by it. Educator 12 explained: 'We are forced to use the document ... I'm not sure if it's user friendly to other people but ... we use the document and try to work from it.'

Aside from some educators regarding the CAPS document as not being user-friendly, certain educators felt that, in addition, the expectations of the CAPS document are idealistically high. This was challenging for both the educators and the learners and was corroborated by Educator 6, who said, 'You cannot expect them to perform at that level.' The fact that these learners were learning through the medium of a second language immediately placed them at a disadvantage, since the best medium for teaching a child is his/her home language (United Nations Children 
Fund 1999: 41, 45; United Nations Educational, Scientific and Cultural Organisation, 1953: 11). Taylor and Coetzee (2013: 6) found that learners in South Africa who were taught in their home language during the first three years of primary school performed better in the English tests in Grades 4, 5 and 6 than children who were exposed to English as the language of instruction in Grades 1, 2 and 3. Furthermore, Walter's study (2013: 1-25) in developing countries such as Cameroon, Eritrea, Guatemala and the Philippines demonstrated that it takes five or six years in a second-language instructional model to approximate the reading skills developed in three years (or less) in a home-language instructional model. Therefore, there is a great possibility that learners could not cope with the level of the CAPS due to their limited proficiency in English. However, Educator 10 maintained that 'even the home language learners struggle.' Educator 11 felt that the curriculum contained '... a lot of work. Lots of activities to be done.' Owing to the large quantity of work to be covered, a learner's absence for even a short period gave no time for the educator to assist such a learner with completing previous work or to revise or explain the material further. This was emphasised by Educator 10, who said, 'If a child misses a day of work there's no going back because it's such a pressurised document. There's no room for you to go back and do remedial work.' Due to its excessive workload for learners, it was felt that Foundation Phase learners could not cope.

Another challenge was that the pace is too fast because of the unrealistic number of assessments. Educators viewed this as unsuitable for the first two terms of Grade 1. Grade 1 is the first year of formal schooling for learners, but the CAPS curriculum planners seem not to have taken into account the transition period from Grade $\mathrm{R}$ to Grade 1. As Educator 12 explained, 'I think that the pace in the CAPS document is not good [slow] enough for the first two terms of Grade 1. That's my initial challenge'. The large number of assessments that had to be completed made the work of assessing learners both onerous and time consuming. Educator 6 emphasised this point, saying, 'We are doing more assessing than actually trying to teach,' as did Educator 13, who asserted, 'Assessments. I can't even say have doubled. There are too many assessments. In the past we knew exactly what we were doing and suddenly when CAPS was introduced we find that there are more assessments than actual teaching.' The number of assessments had clearly increased educators' workload dramatically, and participants were unhappy with the new situation.

The focus of assessment in OBE was general - away from a fixed body of content that had to be remembered, towards a set of outcomes that had to be demonstrated (Vandeyar \& Killen, 2003: 125 ) - and the number of assessments in the RNCS curriculum was not prescribed. The CAPS document, by contrast, demands from a Grade 1, Grade 2, and Grade 3 learner a total of 38, 40, and 49 assessment tasks a year, respectively, for English Home Language only (Department of Basic Education, 2011: 55-129). This is challenging for learners and educators, making educators follow a strict programme of assessing learners each term. The researchers realised that, because of the heavy load of assessment that had to be done each term, there was not much time left to attend to the needs of learners who needed additional support to master English Home Language as their language of learning and teaching.

Phonics is linked to reading and writing. The methodology used when teaching phonics influences learners' progress in reading and the development of young learners' writing skills. Educators felt that the teaching of phonics is not presented in a systematic and sequential manner Per Linguam 2018 34(1):17-32 http://dx.doi.org/10.5785/34-1-767 
in the CAPS document. It does not show progression from simple to complex. This created confusion for the learners. The CAPS document states that 'the suggested sequence of introducing the phonic elements in the CAPS document is a guide' and schools may select the phonics programme that will support explicit and systematic teaching of phonics (Department of Basic Education, 2011: 15). Contrarily, the CAPS document also affirms that, where phonic programmes have different sequences, educators must follow the CAPS document (Department of Basic Education, 2011: 15). Educator 4's view on the teaching of phonics was, 'The way we have phonics in our school doesn't correlate with the way they have arranged their phonics. It's like they have no order of how they are putting their phonics. They are jumbled up'. Since the educators in this study had an average of 20.7 years of teaching experience, it could be that the educators were experiencing difficulty in making the transition from the older curricula and methods of teaching phonics, which they believed were more suitable and worked better, to the CAPS. Educator 10 expressed the problem as follows: 'It's definitely the grammar and story writing because ... when you expect them to apply what they learnt in language to what they write in their stories, they can't. They learn in isolation. They only learn that section for that time period.' It is clear why writing was viewed as difficult in the implementation of the rigidly structured CAPS programme by some of the educators.

Our findings concerning the implementation of the CAPS document in Grade 1 support a study by Bruwer, Hartell and Steyn (2014: 27-30). Just two years after the implementation of CAPS, they found that the predominant concerns of the Grade 1 educators in their study in two urban schools in Pretoria were that:

The pace and expectations of the new curriculum (CAPS) are unrealistic and the workload is too heavy; they have no choice but to start with formal work even though they know that learners are not ready for it; they are not allowed enough time in the curriculum to lay a proper foundation; and they have to spend too much of their teaching time on formal assessment.

This is the fifth year since the implementation of CAPS and no action has been taken to improve the Foundation Phase English Home Language CAPS document. It is our view that feedback from educators in the present study could assist in suggesting ways to revise and improve the CAPS. Unfortunately, with the implementation of the new CAPS document, the Department of Basic Education does not make provision to listen to the 'voice' of educators who have to implement the new document and, in our view, this is something that needs to be done.

\section{Educators' views on the Foundation Phase English Home Language CAPS workbook}

According to the Department of Basic Education (2014: 17), workbooks reduce the administrative burden on educators and set out exercises for each week of the year. It was disheartening to note the disjunct between the Department of Education's vision and the educators' experiences of using the workbooks in practice. Most of our participants expressed dissatisfaction with the CAPS English Home Language workbook. An important concern was the language in the CAPS workbook. Educator 7 stated, 'The language is not completely correct according to proper English language. Sometimes I find things that are incorrect.' The Foundation Phase is a critical period in which learners are exposed for the first time to formal 
reading and writing activities. Learners may learn incorrect language structures due to language errors in the workbook. The Department of Basic Education should ensure that the language in the CAPS workbook is edited prior to printing.

Another challenge was the level of the workbook. Educators felt that the workbook is too complex and not appropriate for the learners' actual stages of development; therefore, it was viewed as confusing for the learners. For example, as Educator 5 explained, the stories in the Grade 3 workbook were difficult for learners to read and understand: 'There's no way our kids at Grade 3 level are going to read those stories all on their own and understand because there are quite a few words that are very difficult.' Educator 10 believed that 'the English for Grade 3 is very difficult for second language learners. The language book is not very user friendly.' Educator 8 complained, 'It is so condensed and I think it's confusing for them. I think it's too much for Grade 1. The workbook is too much and it's frustrating for the teacher and the children.' It is probable that the learners in these schools were not ready for formal schooling in English medium schools since they were admitted to Grade 1 at the age of five. These young learners would not have had a solid foundation in their first language and they were required to learn through the medium of a second language. However, Educator 10 argued: 'Even the home language learners struggle'. When making curricula changes, the Department of Basic Education should consider the plight of the thousands of English second language learners who attend English medium schools.

According to the CAPS document, the content and context of each grade shows progression from simple to complex (Department of Basic Education, 2011: 4). However, the present study has shown that the teaching of phonics by means of the CAPS workbook does not progress from simple to complex, it is not sequential and it is confusing for the learners. All the educators interviewed were dissatisfied with the phonics structure in the CAPS workbook. Educator 7 was insistent: 'I'm not happy with the phonics ... It's very scrambled ... They are doing five or six new sounds on one page. It's very confusing for the child. Maybe if they had it structured it would have made more sense.' Educator 10 had the same problem: 'Personally I don't like the phonics in CAPS at all because it's very helter-skelter. It does not follow that logical sequence ... It is just not structured for children who are second language speakers ... Even the home language learners struggle.'

The interviews revealed that educators preferred the traditional method of teaching phonics, in which the single sounds are taught first. Blends are introduced only after all 26 single sounds have been taught. Educator 8 found it easier to teach in that way, 'Because I'm teaching for so long I'm still following the old method and I do not follow the CAPS phonics.' Educator 10 was contemplating a similar strategy: 'I'm not in favour of that phonics. In fact, I considered going back to my old method.' Educator 13 highlighted the problem: 'I remember phonics many years ago when we started with basic phonics. We started with single sounds, going to blends, and then to more advanced stages of phonics but what we find here is that the phonics is not starting at the basic and going up. It's all mixed up.'

Per Linguam 2018 34(1):17-32

http://dx.doi.org/10.5785/34-1-767 
The educators' concerns about teaching phonics should be considered seriously in future planning, as this section of the curriculum plays a significant role in reading and writing. In the opinion of the researchers, educators with teaching experience in the Foundation Phase should be allowed the freedom to use and teach phonics in the way that they have done successfully over years. Foundation Phase learners are taught to sound the words when reading and writing. If phonics is not taught systematically, learners may later experience difficulty with reading and spelling. However, phonics should not be taught in isolation. It should also be taught incidentally. Educators should integrate phonics with speaking, reading, spelling and writing. Since the English language contains a large percentage of words that are not spelt as they sound, it is important to teach sight words. Story reading will assist learners to recognise whole words on sight. Learners can build a sight vocabulary through incidental reading of the basic high frequency words. Educators should rather be encouraged and should receive in-service training to combine the traditional method of teaching phonics with the whole-language approach when they teach reading. The combined approach is considered the best approach to teach reading.

The fact that the educators in this study were discontented with the structuring of the phonics raises the question of whether these workbooks were being used optimally in the classroom. Additional research could usefully obtain the opinions of more Foundation Phase educators.

The interviews yielded a few positive responses about the workbook. Two educators appeared to be satisfied with many aspects of it, apart from the phonics. They felt that the stories in the workbook are good in terms of the learners' levels of development. Young learners enjoy reading books with colourful, bold pictures, so the fact that the stories in the workbook are accompanied by colourful pictures creates interest. Therefore, Educator 6 expressed satisfaction with this aspect of the workbook: 'I think it's quite good. They enjoy the stories. I like this book because it gets them to think ... It's always recalling, repetition and it's based on a story. The passages there are not too difficult for them. It's using children's names that they are familiar with. The fact that the books are in colour, the pictures, it's all appealing to them.' Educator 9 commented, 'I find it very helpful. The Grade 3 one is really helping me because there's a lot of variation in terms of questioning and in terms of how they answer... Lots of lovely stories. The stories are very nice and the children enjoy it ...'

Initially, the Australian Council for Education Research (ACER) and the United Nations Children's Fund (UNICEF) conducted an evaluation of the CAPS workbooks on behalf of the Department of Basic Education (McKay, 2013: 20). They surveyed the use of the workbooks in 327 schools and reported that most educators found the workbooks to be extremely useful. What ACER and UNICEF failed to evaluate, however, were the expectations of the Foundation Phase English Home Language workbook relating to the teaching of phonics.

According to the Department of Basic Education (2014: 17), the implementation of CAPS, combined with the national workbooks, provide better guidance to educators than was previously available. The present study, however, has shown that educators still experience difficulties with implementing CAPS, largely because of the disassociation between the CAPS and the classroom

Per Linguam 2018 34(1):17-32

http://dx.doi.org/10.5785/34-1-767 
conditions in which they work, and because of some areas of the curriculum with which they struggle, such as the phonics and the number of assessments. These are areas that would need careful reconsideration and possible revision.

\section{CONCLUSION}

The aim of this study was to investigate experienced educators' perceptions of the Foundation Phase English Home Language CAPS, with a view to understanding which aspects could be targeted for improvement, and to assist with addressing growing concerns about the inadequate reading abilities of the majority of learners in South Africa. We have followed the call by Magagula (2016: 1) that 'teachers need to be actively involved during the [CAPS document] review process.'

Reading starts in the Foundation Phase and, since phonics plays a crucial role in reading, it should be structured to make it easy for young children to learn. A key finding, therefore, is that the phonics in the Foundation Phase English Home Language CAPS document and workbook was viewed as not well structured; this area would seem to require revision to enable educators to teach it systematically and to enable learners to understand and apply it better as they learn to read and write.

Another crucial finding is that the large number of assessments is a challenge for both educators and learners. This shortcoming reduces parts of CAPS to what is perceived as a set of onerous, prescriptive, administrative requirements, rather than a way to assist with improving literacy levels. It suggests that educational planners should consider reducing this number in the Foundation Phase English Home Language CAPS document, to create a better balance between time spent teaching and time spent on assessment. The educators' views on the writing tasks should also be taken seriously, coming as they do from the people who know best what their learners in the Foundation Phase can realistically accomplish.

A further issue is the pace required by the CAPS document for the first two terms of Grade 1 when young learners are at the very start of their formal schooling. And, combined with an overrigorous pace, the rigid structure of the Foundation Phase English Home Language CAPS document, in the view of our participants, seems to fall short of providing educators with sufficient time to teach young children genuinely to master the reading and writing skills that they will need for all the years of schooling that follow.

Lack of consultation with educators is a contributing factor to the failure of CAPS (Maharaj et al., 2016: 380-381); and this study, despite its limited scale, highlights the unique benefits of involving educators directly as critical stakeholders in the education process. They are the ones who have to put a curriculum into practice in the classroom, so their expert input could form an invaluable component in routine curriculum planning and development processes. Their input about educators' specific teaching needs could also be relevant for the planning of in-service training. Our project opens the door to future small- as well as larger-scale studies to ask for assistance with issues arising from CAPS implementation from the educators with first-hand experience of it. In this way, instead of the dramatic (and often traumatic) curriculum 
replacements of the past two decades, systematic ongoing curricular improvement can become the way ahead for South African education.

\section{ACKNOWLEDGEMENTS}

We wish to thank the educators who participated in this study, all those who gave permission for it to be conducted, and Dr Elisabeth Lickindorf for her editorial input.

\section{REFERENCES}

BOTHA, RJ. 2002. Outcomes-based education and educational reform in South Africa. International Journal of Leadership in Education, 5(4):361-371.

BRUWER, M, CG HARTELL \& MG STEYN. 2014. Inclusive education and insufficient school readiness in Grade 1: Policy versus practice. South African Journal of Childhood Education, 4(2):18-35.

CHISHOLM, L. 2003. The politics of curriculum review and revision in South Africa. Available from www.hsrc.ac.za/en/research/-outputs/ktree-doc/985 [Accessed: 12 August 2017].

CRESWELL, JW. 2009. Research design: Qualitative, quantitative, and mixed methods approaches $\left(3^{\text {rd }}\right.$ ed.). Thousand Oaks, CA: Sage.

DEPARTMENT OF BASIC EDUCATION. 2011. Action plan to 2014. Towards the realisation of schooling 2025. In: ANC (Ed), Education summit 12-13 April 2012. Consolidating towards the achievement of quality education. South Africa: Umrabulo. 287-438.

DEPARTMENT OF BASIC EDUCATION. 2011. National Curriculum Statement. Curriculum and Assessment Policy Statement. Foundation Phase. Grades R-3. English Home Language. Pretoria: Department of Basic Education.

DEPARTMENT OF BASIC EDUCATION. 2014. Annual performance plan 2014-2015. Pretoria: Department of Basic Education.

DEPARTMENT OF EDUCATION. 2002. Revised National Curriculum Statement Grades $R-9$ (Schools). Pretoria: Department of Education.

DEPARTMENT OF EDUCATION. 2009. Report of the task team for the review of the implementation of the National Curriculum Statement. Pretoria: Department of Education.

DONALD, D, S LAZARUS \& P LOLWANA. 2010. Educational psychology in social context. Ecosystem applications in Southern Africa $\left(4^{\text {th }}\right.$ ed.). Cape Town: Oxford University Press.

DÖRNYEI, Z. 2011. Research methods in applied linguistics. China: Oxford University Press.

FLEISCH, B. 2008. Primary education in crisis: Why South African school children underachieve in reading and mathematics. Cape Town: Juta.

FOUCHÉ, CB. 2005. Qualitative research designs. In: AS De Vos, H Strydom, CB Fouché \& CSL Delport (Eds), Research at grassroots: For the social sciences and human service professionals ( $3^{\text {rd }}$ ed.). Pretoria: Van Schaik. 267-273.

GORMAN, GE \& P CLAYTON. 2008. Qualitative research for the information professional: A practical handbook. Great Britain: Facet.

GRUSSENDORFF, S. 2014. What's in the CAPS package? A comparative study of the National Curriculum Statement (NCS) and the Curriculum and Assessment Policy Statement (CAPS): FET phase. Overview. South Africa: Umalusi.

JANSEN, JD. 1998. Curriculum reform in South Africa: A critical analysis of Outcomes-based Education.

Available

from

Per Linguam 2018 34(1):17-32

http://dx.doi.org/10.5785/34-1-767 
https://repository.up.ac.za/bitstream/handle/2263/132/Jansen\%20(1998)a.pdf [Accessed: 12 August 2017].

JANSEN, J \& N TAYLOR. 2003. Educational change in South Africa 1994-2003: Case studies in large-scale education reform. Education Reform and Management Publication Series, 2(1):1-61.

KILLEN, R. 1998. William Spady: A paradigm pioneer. Available from https://www.education.sa.gov.au/doc/william-spady-paradigm-pioneer [Accessed: 12 August 2017].

LUNENBERG, FC. 2011. Curriculum development: Deductive models. Schooling, 2(1):1-7.

MAGAGULA, SW. 2016. The township school's foundation phase teachers' experiences in the implementation of CAPS. Available from http://hdl.handle.net/10539/21592 [Accessed: 12 August 2017].

MAHARAJH, LR, T NKOSI \& MC MKHIZE. 2016. Teachers' experiences of the implementation of the Curriculum and Assessment Policy Statement (CAPS) in three primary schools in KwaZulu-Natal. Africa's Public Service Delivery and Performance Review, 4(3):371-388.

MCKAY, V. 2013. The rainbow workbooks brighten our classes. In: Department of Basic Education (Ed.), Curriculum news. Improving the quality of learning and teaching: Strengthening curriculum implementation from 2010 and beyond. Pretoria: Department of Basic Education. 13-120.

MCKERNAN, J. 2008. Curriculum and imagination: Process theory, pedagogy and action research. New York: Routledge.

MCMILLAN, JH \& S SCHUMACHER. 2010. Research in education: Evidence-based inquiry. Seventh edition. New Jersey: Pearson.

NIEUWENHUIS, J. 2016. Analysing qualitative data. In: K Maree (Ed.), First steps in research ( $2^{\text {nd }}$ ed.). Pretoria: Van Schaik. 104-131.

NIEUWENHUIS, J. 2016. Qualitative research designs and data gathering techniques. In: K Maree (Ed.), First steps in research (2 ${ }^{\text {nd }}$ ed.). Pretoria: Van Schaik. 72-102.

O’NEIL, G. 2010. Programme design: Overview of curriculum models. Available from http://www.ucd.ie/teaching [Accessed 12 August 2017].

PUNCH, KF. 2009. Introduction to research methods in education. Great Britain: Ashford.

SPADY, WG. 1994. Outcomes-based Education: Critical issues and answers. United States of America: The American Association of School Administrators.

SPADY, W. 2007. It's time to end the decade of confusion about OBE in South Africa. Available from $\quad$ https://edulibpretoria.files.wordpress.com/2008/08/spadyobeconfusionpaper.pdf [Accessed: 12 August 2017].

STEYN, HJ, SC STEYN \& EAS DE WAAL. 2001. The South African education system: Core characteristics. Pretoria: Content Solutions Online.

TAYLOR, N. 2013. The work of the National Education Evaluation and Development Unit. In: Department of Basic Education (Ed.), Curriculum news. Improving the quality of learning and teaching: Strengthening curriculum implementation form 2010 and beyond. Pretoria: Department of Basic Education. 3-11.

TAYLOR, S \& M COETZEE. 2013. Mother-tongue classrooms give a better boost to English study later. Mail \& Guardian, 18 October. Available from http://mg.co.za/article/2013-10- 
18-mother-tongue-classrooms-give-a-better-boost-to-english-studies-later [Accessed: 1 December 2017].

UNITED NATIONS CHILDREN'S FUND. 1999. The state of the world's children. New York: United Nations Children's Fund.

UNITED NATIONS EDUCATIONAL, SCIENTIFIC AND CULTURAL ORGANISATION. 1953. The use of vernacular languages in education. Paris: United Nations Educational, Scientific and Cultural Organisation.

VANDEYAR, S \& R KILLEN. 2003. Has curriculum reform in South Africa really changed assessment practices, and what promise does the revised National Curriculum Statement hold? Perspectives in Education, 21(1):119-134.

VARIEND, A. 2011. What you need to know about CAPS - Part 1. Available from http://maskewmillerlongman.ning.com/profiles/blogs/what-you-need-to-know-about-CAPS [Accessed: 12 August 2017].

WALTER, S. 2013. Mother tongue-based education in developing countries: Some emerging insights. Available from www.globalpartnership.org/media/library/blog/Steve-WalterMother-Tongue-Insights.pdf [Accessed: 1 December 2017].

WIUM, A. \& B LOUW, B. 2011. Teacher support - an exploration of how foundation-phase teachers facilitate language skills. South African Journal of Communication Disorders, 58(2): $1-7$.

WOOD, E \& H HEDGES. 2016. Curriculum in early childhood education: critical questions about content, coherence, and control. The Curriculum Journal, 1-19. DOI: http://dx.doi.org/10.1080/09585176.2015.1129981.

\section{BIOGRAPHICAL NOTES}

Radhamoney Govender is an educator at Marburg Primary School and a facilitator for the North West University. She has twenty-two years of teaching experience in the Foundation Phase. She has a HED, BA degree, B Ed Honours, M Ed Degree and a D Ed degree. She is involved in research related to education. E-mail: govenderranjini@gmail.com

Anna J Hugo is a research associate in the Department of Language Education, Arts and Culture at UNISA. She was attached to this department as a professor. She is a rated NRF researcher and has published widely. She edited two books on English as a first additional language. E-mail: annajohugo@gmail.com 